\title{
AC 2008-1263: THE EFFECT OF PERSONALITY TYPE ON TEAM PERFORMANCE IN ENGINEERING MATERIALS TERM PROJECTS.
}

Dave Kim, Washington State University-Vancouver

Jaesoon Jang, Washington State University-Vancouver

Sung Jae Shin, Washington State University-Tricity 


\title{
The effect of personality type on team performance in engineering materials term projects.
}

\begin{abstract}
Most of long-term engineering class projects require teamwork. Often, conducting projects increase the quality of classroom life and facilitate student learning. Sometimes, team projects hinder student learning and create disharmony and dissatisfaction with classroom life. In many cases, the mixture of each individual's personality determines team dynamics. The 'Introduction to Engineering Materials' course for junior level students encompasses a semester-long term project, which heavily requires teamwork. The term project should focus on a component of existing manufactured products and show why a particular material is used for a particular application. The experiments chosen should prove or disprove this. Each team will chose a topic, determine how to evaluate that topic, devise relevant experiments, evaluate the results of these experiments and formulate a conclusion. Finally, the students will present their results to the class at the end of the semester. The goal of this study is to see how the team performance can be affected by each individual student's personality type in the term projects of the engineering material course. The personality test used in this study was the DISC test, which is the oldest, most validated, and reliable personality assessment tool. DISC stands for Dominance, Influence, Steadiness, and Conscientiousness, which are the four dimensions in the personality characteristics. For the term project, six teams were formulated. The instructor assigned four or five students to a team. Students with similar personality types were assigned to work with each other in three of the teams. The other three teams have students with well-mixed dimensions in their personality characteristics. This paper presents the effectiveness of using student personality on team building for the semester-long team projects. Overall student experience and lessons learned in organizing such a project are also discussed.
\end{abstract}

\section{Introduction}

Developing effective teamwork skills among undergraduate students is part of the Accreditation Board for Engineering and Technology (ABET)'s engineering criterion 2006- 2007 [1]. Besides the ABET requirements, many employers emphasize the need of good teamwork skills for the engineering graduates [2]. In addition, it is well known that cooperative learning enhance students' learning performances. Under the cooperative learning or teamwork environment, students work together to maximize not only their own, but other students ability to learn [3,4]. Most engineering programs incorporate a number of team projects into their curricula and there are some excellent guidelines on incorporating teamwork into existing courses [5]. A number of studies have been done on how to improve effectiveness of corporative learning or teamwork in engineering classrooms. With no surprise, successful teamwork with proper team functionality 
depends on strong, uniform interaction among the students [6]. Often, team formation is very critical on team building and team member interactions [7].

A team is "a small group of people who are committed to a common purpose, performance goals, and approach for which they hold themselves mutually accountable."[7] Often, teams consist of people with different or similar personalities. Organizational behavior researchers have developed multiple guidelines for assigning people to teams. For the projects with a very challenging nature, teams with diverse personalities and complementary skills work more effectively. Teams with similar personality are more efficient when the projects require high team cohesiveness. When we take a look at the term projects in engineering courses, it is not well known which one is more effective. This paper aims to explain how team formation using student personality influences the team's project outcomes in material engineering term projects.

\section{Four dimensions in personality: DISC}

There are a number of personality classification studies but the DISC assessment is one of the most classic methods to characterize the people's personality. DISC is the four quadrant behavioral model based on the work of Dr. William Moulton Marston to examine the behavior of individuals in their environment or within a specific situation. DISC looks at behavioral styles and behavioral preferences [8].

The DISC tests classify four aspects of behavior by testing a person's preferences in word associations. DISC is an acronym for:

- Dominance - relating to control, power and assertiveness. These people tend to be independent and results driven. They are strong-willed people who enjoy challenges, taking action, and immediate results. The bottom line is their focus tends to be on the bottom line and results.

- Influence - relating to social situations and communication. These individuals tend to be very social and out going. They prefer participating on teams, sharing thoughts, and entertaining and energizing others.

- Steadiness (submission in Marston's time)- relating to patience, persistence, and thoughtfulness. These people tend to be your team players and are supportive, cooperative and helpful to others. They prefer being behind the scene, working in consistent and predictable ways. They are often good listeners and avoid change and conflict.

- Conscientiousness (or caution, compliance in Marston's time) - relating to structure and organization. These people are often focused on details and quality. They plan ahead, constantly check for accuracy, and what to know "how" and "why".

Once people conduct the DISC tests with several survey questions, they can get their points in each dimension, which is called DISC profile. Based on the DISC profile, people can be grouped in one or two personality dimensions. 


\section{Material Engineering term projects and team assignment}

The mechanical engineering program at WSU Vancouver offers a 3-credit materials course, which is named 'Mech 309, Introduction to Engineering Materials' which deals with material structure, phase equilibrium, phase transformations, and mechanical properties of engineering materials. This course contains a semester-long team project, which is $15 \%$ of the total grade. The purpose of the team project is to allow the students to pursue a materials-related question of interest, to some extent. Each team chose a topic, determined how to evaluate that topic, determined relevant experiments, evaluated the results of these experiments and formulated a conclusion. At the end of the semester, each team presented the results of their work to the class. The TA and instructor grade their project outcomes based on the following criteria. Note that this team project is the first open-ended term project that the students do in the upper division engineering course. In addition, they should design, prepare, and conduct the hands-on experiments. This is very challenging for the students.

Mech 309 was offered in the fall semester of 2007. The authors used this class for this study. In the beginning of the semester, students were asked to conduct a free licensed DISC test available on the web [9]. Students should answer 25 sets of questions. Once the students completed the test, they will get the DISC profile with the scores in each personality dimensions. Table 1 shows two DISC profile examples. According to the profiles, student 1 has Dominance (D) as their major personality profile while student 2 shows Conscientiousness (C) as his/her representative personality. A personality dimension with the highest score was used for the student's personality. Therefore, student 1 is grouped as D and student 2 is in $\mathrm{C}$.

Table 1 DISC profile examples

\begin{tabular}{|l|l|l|l|l|}
\hline & Dominance (D) & Influence (I) & Steadiness (S) & Conscientiousness (C) \\
\hline Student 1 & 44 & 32 & 8 & 16 \\
\hline Student 2 & 16 & 20 & 24 & 35 \\
\hline
\end{tabular}

Once the profiles were achieved, they were reported to the instructor. Based on the students' profiles, the instructor assigned the teams. Four or five students were assigned as a team. Three teams have consistent personality $(\mathrm{D}, \mathrm{I}$, or $\mathrm{C})$ in each team. Other three teams are consisted of various personalities in a team. Table 2 shows the team assignments. 
Table 2 Team assignments

\begin{tabular}{|c|c|c|c|c|c|c|c|}
\hline $\begin{array}{c}\text { Team } \\
\#\end{array}$ & $\begin{array}{c}\text { Student } \\
\#\end{array}$ & $\begin{array}{c}\text { Personality } \\
\text { type }\end{array}$ & $\begin{array}{c}\text { Team } \\
\text { characteristics }\end{array}$ & $\begin{array}{c}\text { Team } \\
\#\end{array}$ & $\begin{array}{c}\text { Student } \\
\#\end{array}$ & $\begin{array}{l}\text { Personality } \\
\text { type }\end{array}$ & $\begin{array}{c}\text { Team } \\
\text { characteristics }\end{array}$ \\
\hline \multirow[t]{5}{*}{1} & 1 & $\mathrm{D}$ & \multirow[t]{5}{*}{ Uniform 1(D) } & \multirow[t]{5}{*}{4} & 16 & $S$ & \multirow[t]{5}{*}{ Diverse 1} \\
\hline & 2 & $\mathrm{D}$ & & & 17 & $\mathrm{~S}$ & \\
\hline & 3 & $\mathrm{D}$ & & & 18 & $\mathrm{~S}$ & \\
\hline & 4 & $\mathrm{D}$ & & & 19 & I & \\
\hline & 5 & $\mathrm{D}$ & & & 20 & $\mathrm{D}$ & \\
\hline \multirow[t]{5}{*}{2} & 6 & I & \multirow[t]{5}{*}{ Uniform 2(I) } & \multirow[t]{5}{*}{5} & 21 & $\mathrm{D}$ & \multirow[t]{5}{*}{ Diverse 2} \\
\hline & 7 & I & & & 22 & $\mathrm{~S}$ & \\
\hline & 8 & I & & & 23 & $\mathrm{D}, \mathrm{C}$ & \\
\hline & 9 & I & & & 24 & $\mathrm{D}$ & \\
\hline & 10 & I & & & 25 & $\mathrm{C}$ & \\
\hline \multirow[t]{5}{*}{3} & 11 & $\mathrm{C}$ & \multirow[t]{5}{*}{ Uniform 3(C) } & \multirow[t]{4}{*}{6} & 26 & $\mathrm{D}$ & \multirow[t]{4}{*}{ Diverse 3} \\
\hline & 12 & $\bar{C}$ & & & 27 & $\mathrm{~S}$ & \\
\hline & 13 & $\mathrm{C}$ & & & 28 & $\mathrm{~S}$ & \\
\hline & 14 & $\mathrm{C}, \mathrm{S}$ & & & 29 & $\mathrm{D}$ & \\
\hline & 15 & $\mathrm{C}$ & & & & & \\
\hline
\end{tabular}

4. Engineering materials term project evaluation results

\section{Engineering materials term projects}

After the teams were formed, team members chose their leader or leaders for the team. The team's first task is to identify their topics and turn in the short project proposal to the TA and the instructor. The purpose of this proposal is to encourage students to think clearly about the experiments they propose to carry out, and why. The proposal should be short and concise, briefly covering the scope of the proposed topic. The followings are the proposed project titles in the fall semester of 2007.

- Comparison of Different Types of Safety Glasses

- An examination of the material properties of Screws

- Evaluation of Grade 2, 5, and 8 Bolts

- Testing of Nylon, UHMW, Acrylic, Polypropylene, and Delrin

- Material Testing for Composite Decking

- Mechanical properties of Saw blades

During the semester, each team member worked together to fabricate the samples, conduct the materials testing, analyze the data, and prepare the final presentation. Each team was asked to create a web page and present their work on the last day of instruction.

$\underline{\text { Term project evaluation tools }}$ 
In this study, there is three project evaluation items: students' satisfaction with teammates, student working hours for the project, and the project scores. Among three items, the project scores are the most important project outcome because having better grade is the common goal for the students. Two evaluation tools were used to measure these items. The first tool was the student survey, which asked students' satisfaction with teammates and their working hours for the project. The second was the project scores determined by the TA and the instructor.

Before the team project presentation on the last day of instruction, students conducted a short survey with 5 questions. The questions are the followings:

- I am satisfied with how I get along with others on my team.

- I am satisfied with how I am my teammates work together.

- I am satisfied with the opportunity to make friends with my teammates.

- I am satisfied with the decisions made by me and my teammates.

- How many hours did you work on this team project in total?

The first four questions were asked in order to measure students' satisfaction with their teammates. To count their time spent for the project, the last question was asked. In addition to the last question, the TA and instructor kept track of the working hours at the labs for each team during the semester.

After the final presentations, the TA and the instructor read the project web pages carefully and determine the project scores. The following are 8 items on the project evaluations.

- Is the idea creative? Is the project challenge enough?

- How many types of tests have they done?

- Are the experimental methods proper/adequate?

- Do they use Excel for analysis, synthesis and presentation of their data?

- Are they using proper statistical tools to assess data?

- Do they validate experimental results with respect to assumptions, constraints, and theory?

- Are their conclusions concise and to the point?

- Overall quality of the presentation 


\section{$\underline{\text { Term project evaluation results }}$}

Figure 1 presents the comparisons between uniform teams and diverse teams. No significant differences in the satisfaction with coworkers were found between two groups (Uniform and Diverse). However, we found the discrepancies in students' working hours and project scores. Uniform teams spent about $90 \%$ more on the project than the uniform teams; however, their scores were $10 \%$ less than those of diverse teams. The results will be elaborated with the individual team data.

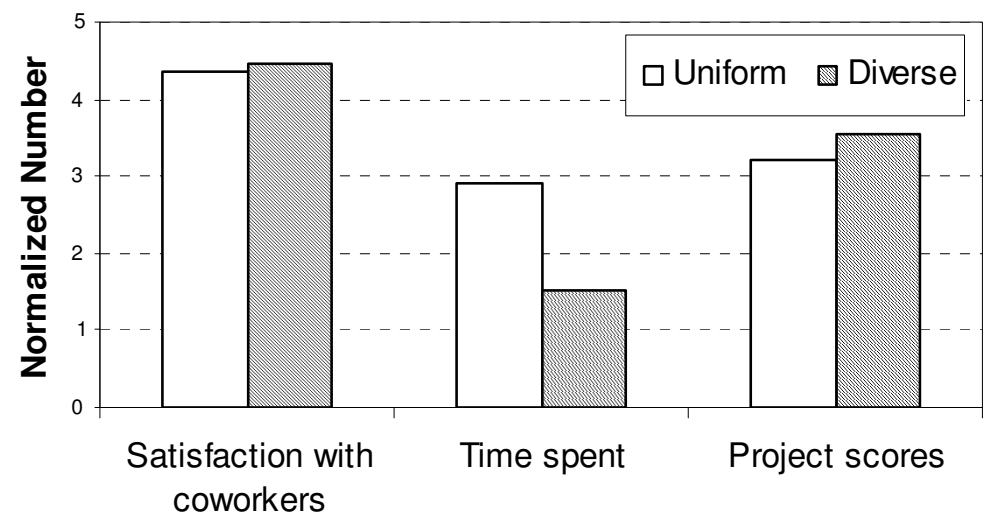

Figure 1. Comparisons between Uniform and Diverse teams

Table 3 shows the three project evaluation items for individual teams. Due to the small number of cases, the statistical approach may not be appropriate in this study. Therefore, some interesting cases will be discussed.

1) Uniform 1 (D) team

This team consisted of students with the personality D (Dominance). People with the personality D enjoy challenges, taking action, and immediate results, and often they want to be in the leadership position. There is an interesting anecdote in this team. When they choose their team leadership, they could not elect one leader. Then, they ended up with everyone as leaders. As a result, too many leaders were observed in that team and the team was not emerging. Their satisfaction with teammates was moderate and they did not spend much time for the project. These two reasons may be the cause of a moderate project score (2.8 out of 5).

2) Diverse 3 (team 6) team

This team consisted of students with the personalities D (Dominance) and C (Conscientiousness). The people with the personality $\mathrm{C}$ are often focused on details and quality and they want to upgrade the surroundings. Note that this team has chosen the most challenging topic and they got the best project score (5 out of 5). The reasons for the best project score included their creative topic, sound methods of approach, superior experimental data analysis/interpretation, and quality presentation. Diverse points of view from diverse personalities might improve the project outcomes. However, this group has 
the lowest satisfaction with teammates. The authors assume this low score came from task conflicts, not from personality conflicts. Due to the difficulties of their topic, the team members had some task conflicts while they conduct the project. The instructor helped them to figure out the solutions on several occasions. The leadership was also very clear in this team and the leader spent a lot of time on the project.

3) Diverse 2 (team 5) team

This team is the mixture of D (Dominance), S (Steadiness), and C (Conscientiousness). The team spent the lowest amount of time for the project and they got the worst score (1.6 out of 5). The first problem with this team was lack of leadership. Everyone was the leader on this team, and this means there was not a clear leadership role. Among six teams, this team spent the fewest hours for the project. The topic was not challenging and therefore the diversity of the team did not affect much on the project outcomes.

Table 3 Results for each team

\begin{tabular}{|c|c|c|c|}
\hline & $\begin{array}{c}\text { Satisfaction with } \\
\text { coworkers } \\
\text { (Scale, 5 the highest) }\end{array}$ & $\begin{array}{c}\text { Each student's } \\
\text { average time spent for } \\
\text { the project } \\
\text { (Hours) }\end{array}$ & $\begin{array}{c}\text { Project scores } \\
\text { (5 to 1, 5 the highest) }\end{array}$ \\
\hline Uniform 1 (D) & 4.55 & 15 & 2.8 \\
\hline Uniform 2 (I) & 4 & 24 & 2.3 \\
\hline Uniform 3 (C) & 4.5 & 28 & 4.5 \\
\hline Diverse 1 (team 4) & 4.7 & 12 & 4 \\
\hline Diverse 2 (team 5) & 4.85 & 11 & 5 \\
\hline Diverse 3 (team 6) & 3.875 & 13 & 1.6 \\
\hline
\end{tabular}

\section{Which one is better? Uniform or Diverse?}

The Mech 309 engineering materials term project requires an organization of project teams, which conduct experiment that require creative problem solving, often involving the application of specialized knowledge. In order to maximize the project team's outcomes and products, there are a lot of conditions to be accomplished. The team should have a clear common goal, leadership, cooperation, trust, and cohesiveness [7]. For the college junior students, the engineering materials term project was quite challenging and complex. They should identify the problems, design the experiments, fabricate the samples, and conduct the experiments. After performing the experiments, they should analyze the data properly and present them at the end. When the nature of the task requires a creative approach and problem solving skills, the group with diverse backgrounds, such as personality, can result in better project outcomes than the uniform group. In addition, leadership was another important factor. Clear leadership can combine diverse team members into one for the project teams. The following recommendations 
can be made based on the results in this study. The teams can be formed with diverse personalities and they should have a clear leadership role for project success.

\section{Conclusions}

The pilot study was conducted to see the effects of team composition on project performance for the semester-long engineering materials term project, which are openended and require hands on experiments. The nature of the project task was challenging and complex, and required creative problem solving skills. Three teams consisted of the same personality profile while the other three teams have diverse personalities. Based on the observations and evaluations, effective leadership and diverse personalities are the key factors to maximize the project outcomes. Therefore, a team formation with diverse personalities and clear leadership can be recommended for the engineering materials term project.

\section{References}

1. ABET (2005). Criteria for Accrediting Engineering programs Effective for the Evaluations During the 2006-2007 Accreditation Cycle. The Engineering Accreditatation Board for Engineering and Technology.

2. Margaret Huyck, Anthony Gaddini, Nishi Gupta, Daniel Ferguson, " Evaluation of a Teamwork Effectiveness Intervention with Interprofessionial Project Teams," Proceedings of ASEE 2006, 16 pages, CD-ROM.

3. Johnson, David W., Johnson, Roger T., and Smith, Karl A. 1991. Cooperative learning: Increasing college faculty instructional productivity." ASHE-ERIC Report on Higher Education. Washington, DC: The George Washington University. 4. Johnson, David W., Johnson, Roger T., and Smith, Karl A. 1991. Active learning: Cooperation in the college classroom. Edina, MN: Interaction Book Company. 5. Oakley, Barbara, Felder, Richard, Brent, Rebecca \& Elhajj, Imad (2004). Turning student groups into effective teams. Journal of Student Centered Learning, 2 (1), 9-34. 6. Katherine Deibel, Team Formation Methods for Increasing Interaction During In-Class Group Work, ITiCSE'05, June 27-29, 2005, Monte de Caparica, Portugal. 7. Robert Kreitner, Angelo Kinicki, Organizational Behavior, MeGraw Hill, 2002.

8. William Moulton Marston, Emotions of Normal People, Routledge, 2002.

9. Free internet DISC test, http://www.mtselect.co.uk/testing/DISC.htm 